\title{
Synonymous Structures in English Syntax
}

\author{
Jemma Militonyan \\ Yerevan State University Ijevan Branch
}

\begin{abstract}
Synonymy is one of the most important sources of the wealth of language and is closely related to the problems of stylistics, speech culture, language changes and language improvements. In linguistic literature the term synonymy is increasingly frequently used in relation to different language elements: sounds, word forms, morphemes, syntactic constructions. Recent developments in the studies of grammatical synonymy have led to a renewed interest in syntactic synonymy which is at the heart of our understanding of grammatical synonyms. The purpose of this article is to review the recent research into syntactic synonymy, taking into consideration the attempts of different linguists to define syntactical synonym, determine the criteria of synonymity and examine the synonymous structures in English syntax.
\end{abstract}

Key words: syntactic synonymy, interchangeability, grammatical meaning, structure, sentence, stylistic shade.

\section{Introduction}

Recently, the study of the phenomenon of grammatical synonymy draws the attention of more and more linguists. The term synonymy originates from a Greek word sunonumon meaning 'having the same name' and it is used to refer to a relationship of similarity or sameness of meaning between two or more words (Jackson \& Amvela 2000:92). In any language we can find some parallel forms and structures that allow us to express the same idea, the same situation and the same grammatical relation in many different ways. Thus we can talk about phonetic synonyms, lexical synonyms, morphological synonyms and syntactic synonyms. Syntactic synonymy is a manifestation of linguistic 
variation of the language which is closely connected with the ambiguity and uncertainty of the extralinguistic world, the extralinguistic variation, which is called the problem of 'choice' in linguistics. No situation or phenomenon can be one-sided either on the level of extralinguistic or linguistic analysis. That is why, different synonymic constructions are used for the reproduction of objectively existing differential aspects of one and the same situation having as a basis the dialectical unity of the commonness of content and the difference of forms of syntactic constructions. Despite the growing interest in the issues of syntactic synonymy, there is still no agreement about the term 'syntactic synonymy', its criteria, the distinction between syntactic synonymy and similar linguistic phenomena.

\section{What is Syntactic Synonymy?}

The phenomenon syntactic synonym is understood in a broad sense. In linguistics there are different approaches to the study of syntactic synonymy. Some definitions of syntactic synonymy are based either on the proximity of grammatical meaning and similar syntactic relations, or the same content or identical common-sense meaning. The term grammatical synonyms was first used by A.M. Peshkovsky. He defined it as "the meanings of words and phrases that are close to each other in terms of their grammatical sense" (Peshkovsky 1930:153). He was interested in expressing the same idea by different linguistic means. According to him, grammatical synonyms are divided into two groups: morphological and syntactic. Peshkovsky includes in syntactic synonyms various cases of convergence in the meaning of many grammatical forms (times, inclinations), various schemes for constructing sentences, prepositions and conjunctions, as well as the possibility of replacing the noun with a pronoun. Before him there were many scientists who referred to the phenomenon of grammatical synonyms though not giving any definition for the term or establishing any criteria of the synonymity of syntactical constructions, such as O. Jespersen (1933:387) who talked about similar grammatical constructions that are interchangeable, the German scientists of the 1920-1930s Trier (1932) and Porzig (1962) who discovered various linguistic means expressing the same idea 
without using the term synonym. They introduced the term grammatical fields which include numerous means chosen by the speaker depending on the estimation and perspective. The Armenian linguist P. Poghosyan paid attention to the problem of the linguistic study of grammatical synonyms. He stated that synonymity should be perceived not only as the substitution of one lexical unit by another, but also as the substitution of meaningful forms and constructions. So, one grammatical form may be substituted by another grammatical form (Poghosyan 1959:18-19). N. Parnasyan writes: "Syntactic synonyms are those phrases, sentences and syntactic constructions that have the same main lexical stock, express the same relations and connections between natural phenomena by different grammatical means, are equivalent to each other and at the same time denote the different attitudes of the speaker towards the conveyed message" (Parnasyan 1970:38). Curme studies synonymic constructions expressing the genitive (the son of the king- the king's son), temporal constructions (the day after I came - the day after my coming), conditional constructions (conditions being favourable - if conditions are favourable), causal constructions (tired and discouraged - since I was tired and discouraged) (Curme 1931:616). But the scientist looks at them from the point of view of the variety of ways of expressing various meanings. Under syntactic synonyms G.I. Richter understands "the facts of semantic equations between whole sentences that differ from each other not only in syntactic structure, but also in stylistic estimates" (Richter 1937:48). M.K. Milikh, without using the term syntactic synonymy, considered the semantic relations of words close in meaning but belonging to different grammatical categories and parts of speech as well as syntactic constructions similar in semantics (Milikh 1945). I. Kovtunova considers syntactic synonyms as "constructions representing a complete grammatical parallelism and differing only in those elements that express the given grammatical meaning" (Kovtunova 1955:28).

In the above definitions, the starting point is the grammatical meaning, which is taken as the basis for the definition of the concept of syntactic synonym.

The American structuralist Wells (1957) also offers an opinion about the omnitude of synonymy in the language. According to him, synonymy is based on 
the possibility to express one content by means of more than one linguistic phenomenon. He assumes that every sign in every language has at least one synonym. In 1950-1960s the representatives of transformational grammar, who recognized the existence of relations of equivalence between transforms, also took an interest in issues of syntactic synonymy. The equivalence relation is a relation of correspondence or involvement and if we refer to the deep and surface structures, in N. Chomsky's terminology it is called cognitive synonymy (Chomsky 1965:162). The differentiation between the deep and surface structures of syntactic constructions provides ground for the formal statement of the ideas of syntactic synonymy. Chomsky studies the variety of syntactically bound surface structures each member of which is directly connected with an abstract underlying representation, has an identical internal structure with other members and is in transformational relations with them; he considers such structures to be synonymous. V.P. Sukhotin defines syntactic synonymy as "such compounds of the same words (word combinations) differing in structure, as well as sentences, their parts and more complex syntactic formations of the given language at a given epoch of its development, which express homogeneous relations and connections of phenomena of real reality" (Sukhotin 1960:160).

\section{The Criteria of Synonymity}

One of the ambiguous issues in the theory of syntactic synonymy is the criteria of synonymity. There are various opinions of scientists on this issue. I.M. Zhilin gives the following definition of syntactic synonyms: "Syntactic synonyms are models of such syntactic constructions (sentences, phrases, word combinations) that have identical or similar meanings, have adequate grammatical meanings, express similar syntactic relations and are capable of substitution in certain contexts" (Zhilin 1974:78). Undoubtedly, we should agree with the statement of I.M. Zhilin in that interchangeability is one of the important criteria of synonymy, because it is the meaning of the phenomenon of synonymy. We are of the opinion that interchangeability is one of the most important criteria of synonymity, since the very generality of grammatical meaning can be revealed only on the basis of interchangeability. But it should be noted that interchangeability should not violate 
the main meaning of correlated constructions and it should take place in equal syntactic environments. Thus, the possibility of such substitutions is strictly limited.

Professor E.M. Galkina-Fedoruk distinguishes the following main features:

1) the semantic commonality, conditioned by the coinciding lexical meaning of the majority of the words entering into synonymous constructions;

2) the possibility of interchange on the basis of a semantic commonality;

3) a different grammatical form, not only in relation to the use of different forms of parts of speech, but also different parts of speech. (Galkina-Fedoruk 1958)

A more correct and recognized point of view on this issue is the opinion of V.P. Sukhotin that one of the most important objective signs of the synonymity of these or other syntactic formations is the possibility of interchange without violating the basic meaning of the combinations being compared. The interchangeability of syntactic constructions is a very significant indicator of synonymy, although the possibilities of this kind are interchangeable (Sukhotin 1960).

In total, the following five criteria are singled out for establishing the synonymity of syntactic models:

1. The possibility of interchangeability of syntactic models in the same syntactic environment.

2. Identity of the semantic meaning of different in structure models.

3. The adequacy of grammatical meaning and, on this basis, the implementation of the same syntactic functions of models in the sentence structure.

4. The generality of the structure of models.

5. The reach of a fairly large class of words that could serve to fill synonymous models.

\section{Syntactic Synonyms in English}

We may find the following synonymous structures in syntax:

1. active and passive constructions if the same arguments are present: 
"And if it does come...Destiny will keep her husband out of France."

(Dickens 1989:187)

...her husband will be kept out of France by Destiny.

Active and passive constructions cannot be considered synonymous if the agent is lost in the passive however clearly it may be identified in the immediate linguistic context, e.g.:

"Ah!" returned the man, with a relish; "he'll be drawn on a hurdle to be half hanged, and then he'll be taken down and sliced before his own face, and then his inside will be taken out and burnt while he looks on, and then his head will be chopped off, and he'll be cut into quarters. That's the sentence."

(Dickens 1989:62)

2. sentences with and without introductory it and there:

"There is a great crowd coming one day into our lives, if that be so," Sydney Carton struck in, in his moody way.

(Dickens 1989:103)

A great crowd is coming one day into our lives...

3. complex or compound sentences and corresponding simple sentences containing nominalized propositional constructions:

- Complex sentence with a subjective clause and a simple sentence when its subject is expressed by gerundial phrase, accusative + infinitive or accusative + participle. E.g.:

"But I think their withdrawing is in your favour."

(Dickens 1989:78)

But I think it is in your favour that they withdraw. 
- Complex sentence with an objective subordinate clause and simple sentence when its object is expressed by the expanded form of infinitive or gerund, for-to infinitive, gerundial phrase, accusative + infinitive or accusative + participle. E.g.:

"...Darnay felt his own hand turn cold in the hand that slowly released and dropped it".

(Dickens 1989:137)

... Darnay felt that his hand was turning cold in the hand that...

- Complex sentence with a relative (attributive) clause and a simple sentence when its attribute is expressed by infinitive (after the words the first, the last, the only, etc. and some superlatives), of + gerund or the participle, often postpositional. E.g.:

“...when Miss Manette's head dropped upon her father's breast, he was the first to see it, and to say audibly...".

(Dickens 1989:77)

...he was the first who saw it and said audibly...

- Complex sentence with an adverbial subordinate clause and a simple sentence when its adverbial modifier is expressed by infinitive or for-to infinitive construction, gerund or its expanded form, present or past participle, absolute participle construction, e.g.:

"The necessity of composing her appearance so that it should attract no special notice in the streets, was another relief."

(Dickens 1989:371)

The necessity of composing her appearance for not attracting any special notice in the streets, was another relief. 
- Main clause of a complex sentence or one of the clauses of a compound sentence is synonymous with a participle functioning as an adverbial modifier of a simple sentence. E.g.:

The rider stooped, and, casting up his eyes at the guard, handed the passenger a small folded paper.

(Dickens 1989:10)

The rider stooped, cast up his eyes at the guard and handed...

4. a simple sentence with direct word order and similar sentence with an inverted subject (infinitive or gerund) replaced by expletive it. E.g.:

To avoid attracting notice, and to give as little occasion as possible for talk and envy, was the general desire.

(Dickens 1989:294)

It was the general desire to avoid attracting notice and to give as little occasion as possible for talk and envy.

\section{Grammatical Synonyms and Style}

"It is very hard to list absolute synonyms: words which are identical both in denotation or basic conceptual meaning, and in their connotations, and so which can be interchanged in all contexts. Most natural languages make do with nearsynonyms, words which are 'similar' in meaning, but which vary in their stylistic values. So, laryngitis and sore throat have the same denotational meaning, or conceptual equivalence, but differ in their context of use: the first more technical than the second. Many apparent synonyms have different collocational ranges: we speak of tall or high buildings, but only of tall people and high mountains." (Wales 2014:412). The same is true for grammatical synonyms. It should be noted that grammatical forms may differ in connotative power; they grow in connotation in accordance with the nature of the meanings connected with them. There are no absolute synonyms in grammar as the synonymic forms commonly have shares of difference in style and purpose. They must harmonize 
with the context as appropriate to a given situation. So the change in synonymous grammatical forms often supposes a change in style. According to the principle of compositionality, the meaning of an expression depends not only on the meaning of its constituents but also on the syntactic form of the expression. To acquire a sense of their right use one should study them in context in the light of their relations with other grammatical devices. Knowledge of synonymic differentiation between the grammatical forms permits a systematic, objective investigation and description of style. According to L. Yezekian: "Where there is a choice of linguistic units and ambiguity, there are synonyms or synonymity. Stylistics studies the choice and uses of synonyms. Thus synonymity is rightly considered to be one of the most important and fundamental objects of stylistic research" (Yezekian 2003:197). D. Bolinger establishes the principle of nonsynonymy of grammatical forms: "a difference in syntactic form always spells a difference in meaning” (Bolinger 1968:127). When considering syntactic synonymy, the Russian linguist Piotorovsky is primarily interested in the stylistic side of the question, since in his opinion syntactic categories are usually revealed in the form of several stylistic synonyms, each of which has its own additional stylistic shades (Piotorovsky 1960).

\section{Conclusion}

All things considered, we may state that syntactic synonyms are the units of a syntactic level that share predicate-argument propositional structure and function, but differ in subjective modality and grammatical structure. One of the most important criteria of synonymy is interchangeability, which should take place in equal syntactic environments. Another key point to remember is that synonymic forms commonly have shares of difference in style and purpose. They must harmonise with the context as appropriate to a given situation. As a result the change in synonymous grammatical forms often supposes a change in style.

\section{References:}

1. Bolinger, D. (1968) Aspects of Language. New York: Harcourt, Brace, and World. 
2. Chomsky, N. (1965) Aspects of the Theory of Syntax. Cambridge: MIT.

3. Curme, G.O. (1931) A Grammar of the English Language. Syntax. New York: Heath and Co.

4. Galkina-Fedoruk, Ye.M. (1959) Sinonimy v russkom yazyke. / Russkiy yazyk v shkole. N 1.-S. 6-13. 41. M.: Uchpedgiz.

5. Jackson, H. \& Amvela, E. Zé (2000) Words, Meaning and Vocabulary (An Introduction to Modern English Lexicology). London: Continuum.

6. Jespersen, O. (1933) Essentials of English Grammar. London: Allen \& Unwin.

7. Kovtunova, I.I. (1955) O sintaksicheskoy sinonimike / I. I. Kovtunova // Voprosy kul'tury rechi. Vyp. 1. - S. 25-30. Moskva.

8. Milykh, M.K. (1945) Voprosy grammaticheskoy stilistiki. // K sinonimike chastey rechi. «Russkoe yazykovedenie». Vyp. 1. S. 31-96. Rostov n/D.

9. Peshkovskiy, A.M. (1930) Printsipy i priemy stilisticheskogo analiza i otsenki khudozhestvennoy prozy. // Voprosy metodiki rodnogo yazyka, lingvistiki i stilistiki. M.; L.: Gosizdat, S. 133-161.

10. Piotrovskiy, R.G. (1960) Ocherki po stilistike frantsuzskogo yazyka. Morfologiya i sintaksis Tekst. / R.G.Piotorvskiy. L.: Nauka.

11.Porzig, W. (1962) Das Wunder der Sprache, 3 Aufl. Bern: Franke Verlag.

12.Rikhter, G.I. (1937) Sintaksicheskaya sinonimika v sovremennom russkom literaturnom yazyke (stilisticheskie nablyudeniya). // Russkiy yazyk v shkole. N 3. S. 14-33.

13.Sukhotin, V.P. (1960) Sintaksicheskaya sinonimika v sovremennom russkom yazyke. Glagolnye slovosochetaniya. Moskva.

14.Trier, J. (1932) Der Deutsche Wortschatz im Sinnbezirk des Verstandes, Hdlb: Carl Winter Universitatverlag.

15.Wales, K. (2014) A Dictionary of Stylistics. $3^{\text {rd }}$ edition. Routledge, New York.

16.Wells. R. (1957) To What Extent Can Meaning be Said to be Structural. I Reports for the eighth international congress of Linguists. Oslo: Oslo University Press, pp.216-232.

17. Yezekyan, L.K. (2003) Hayots lezvi votchagitutyun.Yerevan: YPH.

18. Zhilin, I.M. (1974) Sinonimika $v$ sintaksise sovremennogo nemetskogo yazyka. Krasnodar. 
19. Parnasyan, N.A. (1970) Sharahyusakan homanishnery zhamanakakits hayerenum. Yerevan: HSSH GA hrat.

20. Poghosyan, P. (1959) Bayi yeghanakayin dzeveri votchakan kirarutyunnery ardi hayerenum. Yerevan: YPH.

\section{Sources of Data:}

1. Dickens, Ch. (1989) A Tale of Two Cities. New York: Bantam Dell.

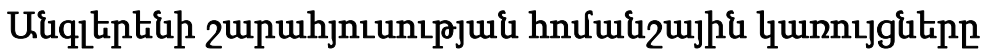

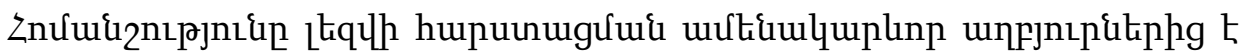

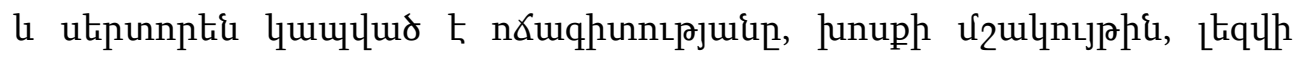

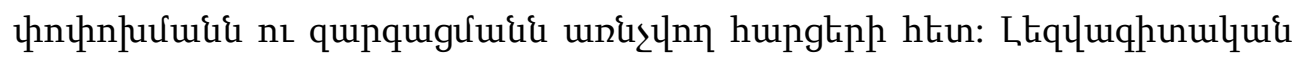

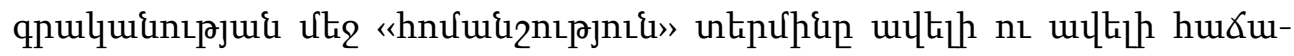

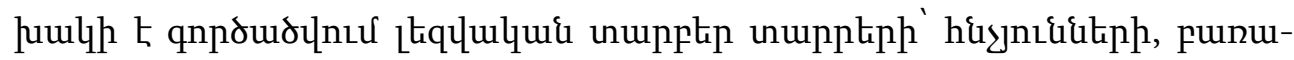

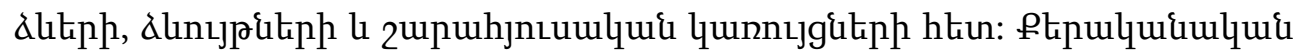

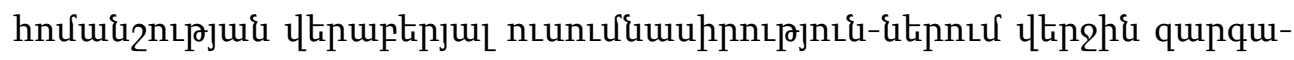

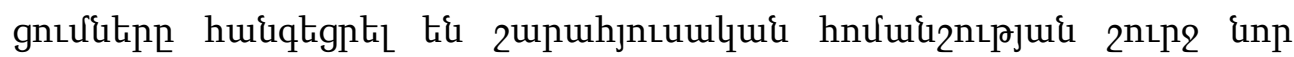

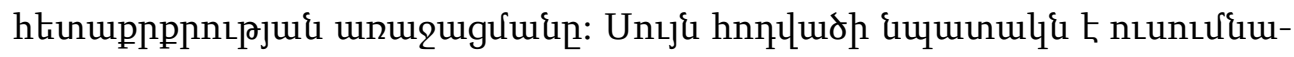

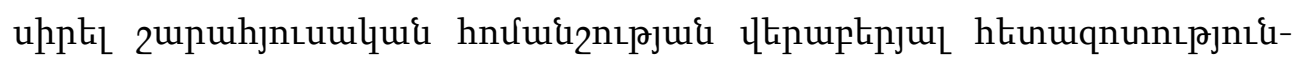

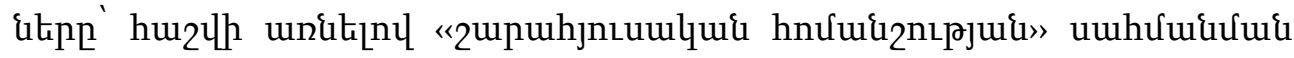

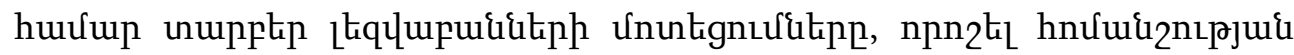

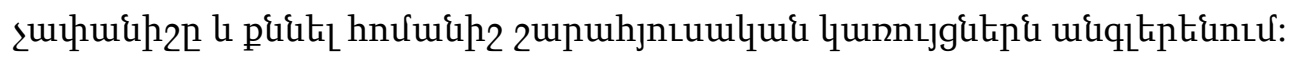

